\title{
Cystic fibrosis and coeliac disease: coexistence in two children
}

\author{
MARY C. GOODCHILD, R. NELSON, and CHARLOTTE M. ANDERSON \\ From the Institute of Child Health, University of Birmingham, and the Children's Hospital, Birmingham
}

Goodchild, M. C., Nelson, R., and Anderson, C. M. (1973). Archives of Disease in Childhood, 48, 684. Cystic fibrosis and coeliac disease: coexistence in two children. Two children, unrelated, in whom cystic fibrosis had been diagnosed at the ages of 14 weeks and 10 months, respectively, were found subsequently to suffer from coeliac disease as well.

Both children are responding well to dietary gluten withdrawal and to conventional treatment for cystic fibrosis.

It is suggested that cystic fibrosis may predispose to the development of coeliac disease. Therefore, jejunal biopsy may be a useful investigation in the occasional child with cystic fibrosis, who presents with unusual features, and who fails to thrive as well as expected.

The coexistence of cystic fibrosis and coeliac disease, in a single child, has been reported by Hide and Burman (1969). A consideration of the separate incidence rates of the two diseases suggests that the probability of finding children affected by both diseases is extremely small.

Two further children who satisfy criteria for both conditions are here described. An attempt is made to decide whether the occurrence of these two diseases together in single individuals is a matter of coincidence, a predisposition for the development of one disease in the presence of the other, or whether the situation may be explained by the existence of an entirely new symptom complex.

\section{Case reports}

Case 1. A girl, birthweight $2 \cdot 47 \mathrm{~kg}$, the younger child of unrelated parents, was born by normal delivery after a normal pregnancy of 38 weeks. Loose, sour smelling motions and an occasional cough were noted from birth. A diagnosis of cystic fibrosis (CF) was made by sweat test at the age of 14 weeks. Pancreatic supplements were then provided with meals. Pneumonia occurred at 6 months, and resolved with antibiotic treatment. There was no family history of note.

The child made slow progress during her first 18 months, and weight gain was poor (Fig. 1). However, motor development during this time was normal, and she had been walking since the age of 15 months.

At 19 months of age she was referred to our unit after 4

Received 14 February 1973. weeks of apathy, vomiting, and refusal to eat. She was a small, listless hypotonic child, who was irritable when disturbed, and made no effort to stand (Fig. 2a). Height and weight measurements were below the 3 rd centile (Fig. 1), the skin was dry and scaly, the hair dry and blonde. Her abdomen was distended, but there was no clinical evidence of chest infection.

As the clinical course seemed unlike that of a patient with CF with minimal chest infection, the diagnosis was reconsidered. Raised sweat sodium and chloride levels were obtained on two occasions (sodium 116 and 80 $\mathrm{mEq} / \mathrm{l}$., chloride 113 and $108 \mathrm{mEq} / \mathrm{l}$.). Duodenal fluid obtained on two different days contained negligible amounts of trypsin and lipase.

Despite a full regimen of treatment for CF in the form of antibiotics, physiotherapy, pancreatic and vitamin supplements, she continued to vomit once or twice daily, and did not gain weight. As she remained irritable and hypotonic with abdominal distension, coeliac disease was considered as a possible explanation. The peroral jejunal mucosal biopsy revealed a very abnormal mucosa : predominantly flat, with a few very stunted villi, and with irregularly cuboidal surface cells. There was an increase of lymphocytes and plasma cells in the lamina propria (Fig. 3a).

This child had ingested very little gluten since admission owing to her anorexia and the fluid nature of her diet; now, however, in addition to the therapy for CF, she was placed on a strict gluten-free diet and disaccharides were exluded also. During the first week of this combined treatment there was a further deterioration in her condition, with more marked

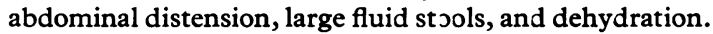
After intravenous therapy and a 10-day course of 

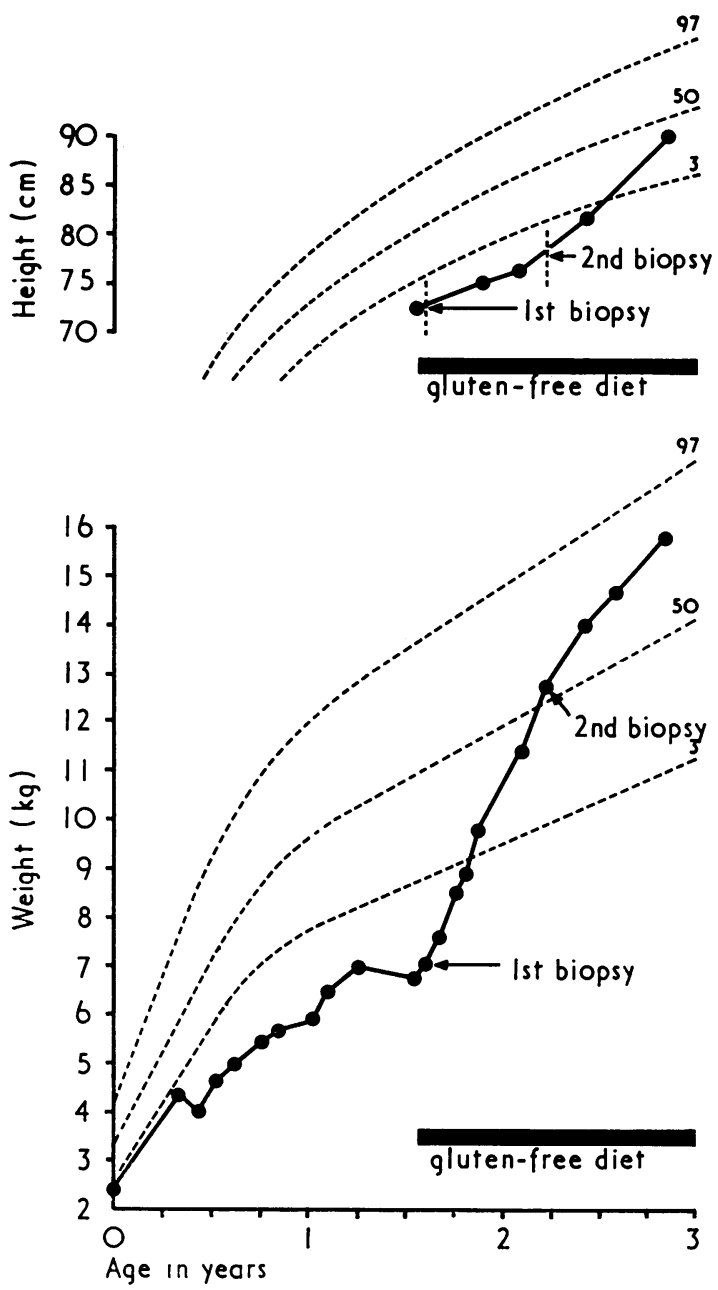

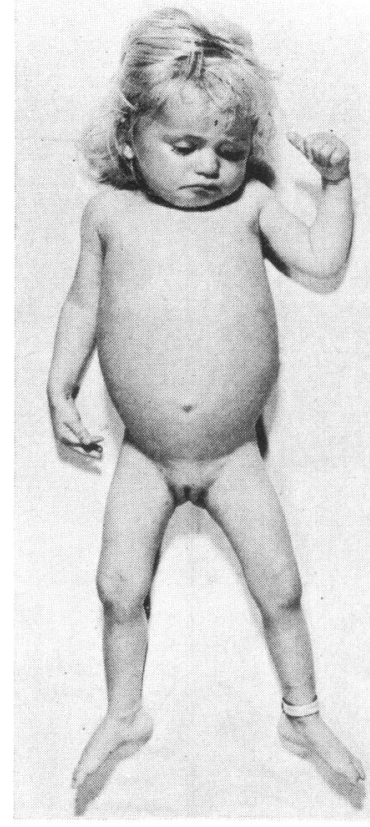

(a)

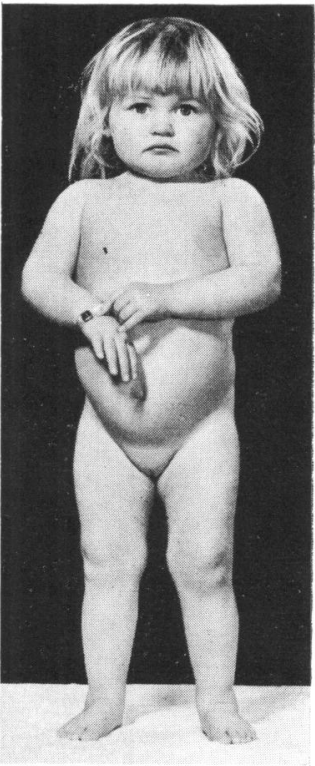

(b)

FIg. 2.-Case 1. (a) Aged 19 months before gluten withdrawal. (b) Aged 27 months, 8 months after gluten withdrawal.

Case 2. A girl, birthweight $3 \cdot 2 \mathrm{~kg}$, was born after a normal pregnancy and delivery to unrelated parents. Intermittent wheezing, associated frequently with vomiting, was noted from the age of 6 months, and persisted until her first birthday. A diagnosis of CF was made by sweat test at 10 months, and subsequently a younger sister also was found to have CF.

Progress until the age of 3 years was uneventful, with very little vomiting and a moderately good weight gain (Fig. 4). Thereafter, periodic vomiting, food refusal, and a moody temperament were prominent features, and no gain in weight was achieved. Vomiting for 4 weeks, diarrhoea for 3 weeks, and a stiffening of the fingers and toes with difficulty in walking for 5 days preceded her admission at the age of 6 years 2 months. She was an alert intelligent child, moderately dehydrated with carpopedal spasm of the extremities, and with evidence of recent weight loss. Examination of the lung fields revealed an increased resonance only. The abdomen was somewhat distended but soft with normal bowel sounds, and the liver was palpable $1 \mathrm{~cm}$ below the costal margin and tender.

Investigations relating to calcium metabolism showed a serum calcium of $5.2 \mathrm{mg} / 100 \mathrm{ml}$, serum phosphorus $3.2 \mathrm{mg} / 100 \mathrm{ml}$, serum alkaline phosphatase $11 \mathrm{KA}$ units, total serum protein $3.5 \mathrm{~g} / 100 \mathrm{ml}$ (albumin 1.7 and globulin $1.8 \mathrm{~g} / 100 \mathrm{ml}$ ); there was no albuminuria. Capillary blood $p \mathrm{H}$ was $7 \cdot 52$, capillary blood $\mathrm{PCO}_{2} 42$ $\mathrm{mmHg}$, and blood urea and electrolyte levels were within 
Fig. 3.-Case 1. Jejunal mucosal hiopsies (a) before complete gluten withdrawal ( $H$ and $E . \times 40.),(b) 8$ months after gluten withdrawal ( $H$ and $E . \times 40.),(c) 8$ months after gluten withdrawal $(P A S . \times 131$.$) .$ 


\section{Cystic fibrosis and coeliac disease}
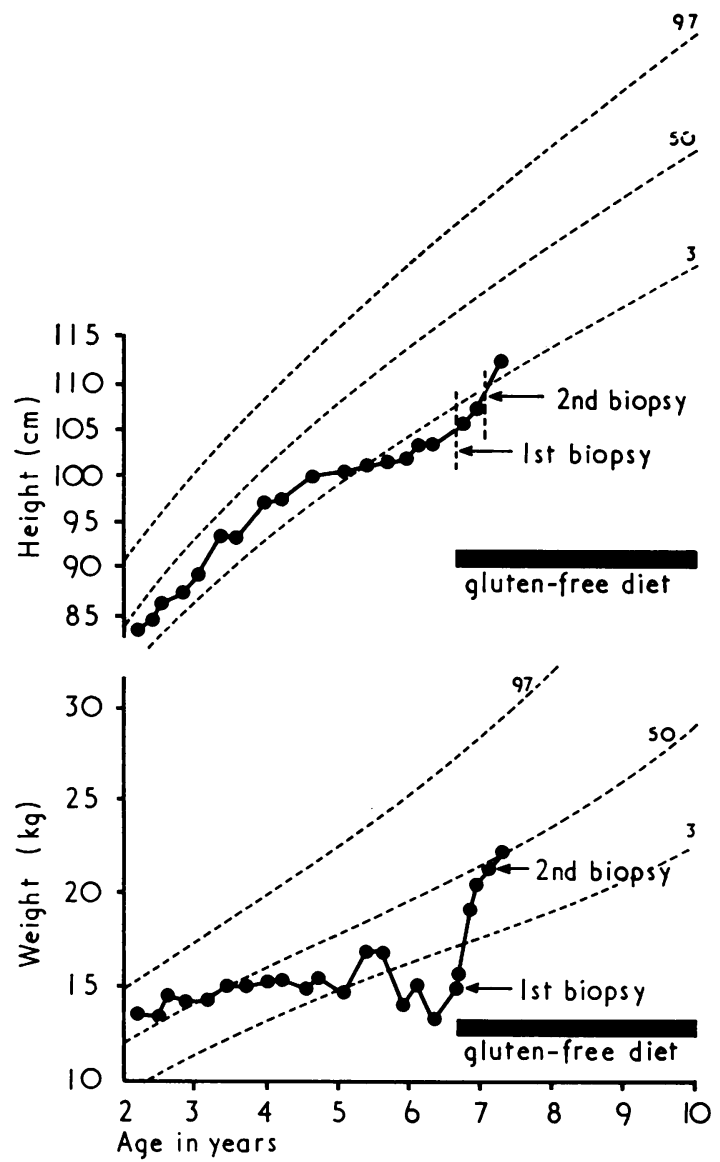

Fig. 4.-Case 2. Height and weight measurements showing response to gluten-free diet.

normal limits. Liver function tests gave a prothrombin time of 62 seconds, SGOT $115 \mathrm{IU}$, and SGPT $60 \mathrm{IU}$. A barium swallow was said to indicate the presence of oesophageal varices.

Sweat sodium and chloride values of 88 and $95 \mathrm{mEq} / 1$., respectively, and trypsin and lipase levels in duodenal fluid of 2.8 units $/ 100 \mathrm{ml}$ for trypsin (azoalbumin, normal value $>8$ units) (Tomarelli, Charney, and Harding, 1949 ) and 0.1 units $/ 0.1 \mathrm{ml}$ for lipase (normal value $>2$ units) confirmed the diagnosis of $\mathrm{CF}$.

Average faecal fat excretion over a 3-day period when pancreatic supplements were given was $6.8 \mathrm{~g} / 24 \mathrm{hr}$. Other tests suggesting a defect in intestinal absorption were serum cholesterol $85 \mathrm{mg} / 100 \mathrm{ml}$, magnesium 0.7 $\mathrm{mg} / 100 \mathrm{ml}$, iron $27 \mu \mathrm{g} / 100 \mathrm{ml}$; serum folate $1.4 \mathrm{ng} / \mathrm{ml}$, red cell folate $108 \mathrm{ng} / \mathrm{ml}$; blood xylose, measured 1 hour after a $5 \mathrm{~g}$ oral dose, was $8.0 \mathrm{mg} / 100 \mathrm{ml}$ (untreated coeliac patients $<20 \mathrm{mg} / 100 \mathrm{ml}, \mathrm{C}$. J. Rolles and M. J. Kendall, personal communication, 1973). A raised urinary excretion of 5-hydroxyindoleacetic acid of $18 \cdot 5$ $\mu \mathrm{g} / \mathrm{mg}$ creatinine per 24 hours, was compatible with a diagnosis of coeliac disease (Challacombe et al., 1972).

$X$-rays showed generalized skeletal calcium deficiency and some infection in the left lower lobe of the lung; bone age was 3 to $3 \frac{1}{2}$ years. Plain abdominal films taken on admission showed faecal mottling in the colon with fluid levels in the small and large bowel consistent with the appearances of 'meconium ileus equivalent'. Two weeks later the barium meal and follow through and barium enema examinations were normal.

Clinical course. The patient was rehydrated via intravenous and oral routes, and received also calcium, magnesium, vitamin $D$, and vitamin $K$. The diarrhoea was thought to be mainly spurious, and associated with the state of meconium ileus equivalent. On this supposition, $\mathbf{n}$-acetyl cysteine was given by mouth as a $5 \%$ solution (Gracey, Burke, and Anderson, 1969) and by enema as a $10 \%$ solution, and the diarrhoea subsided over a 2-week period. Biochemical parameters reverted gradually to normal, though SGOT and SGPT were still somewhat raised at the time of her discharge.

Some difficulty was experienced in correlating all the clinical and laboratory findings with a diagnosis of $\mathrm{CF}$ alone, and other disorders such as coeliac disease, liver disease, and a state of protein-losing enteropathy, were considered as well. However, gradual clinical improvement, though incomplete, led us to forego further investigations at this time. During the next 4 months she progressed fairly well at home, apart from a slow fall in $\mathrm{Hb}$ level from $11 \mathrm{~g} / 100 \mathrm{ml}$ to $8.8 \mathrm{~g} / 100 \mathrm{ml}$, which responded to intramuscular iron.

In February 1972 there was a recurrence of anorexia, vomiting, and parasthesia lasting two weeks, and she was re-admitted. At this time she was a thin girl with some pallor, hypotonia, and abdominal distension (Fig. 5a).

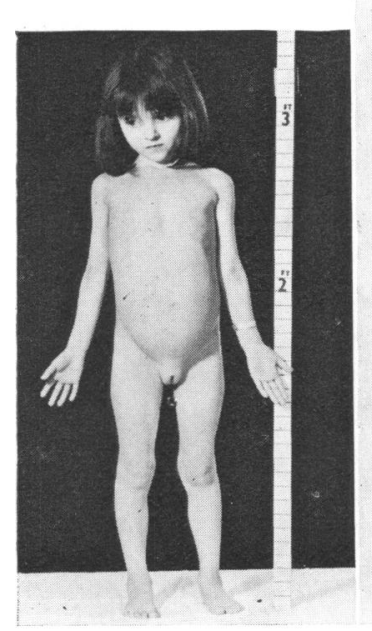

(a)

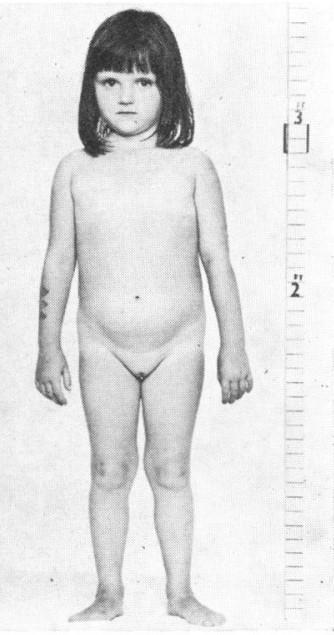

(b)
Fig. 5.-Case 2. (a) Aged 6 years 8 months, before gluten withdrawal. (b) Aged 7 years 1 month, 5 months after gluten withdrawal. 

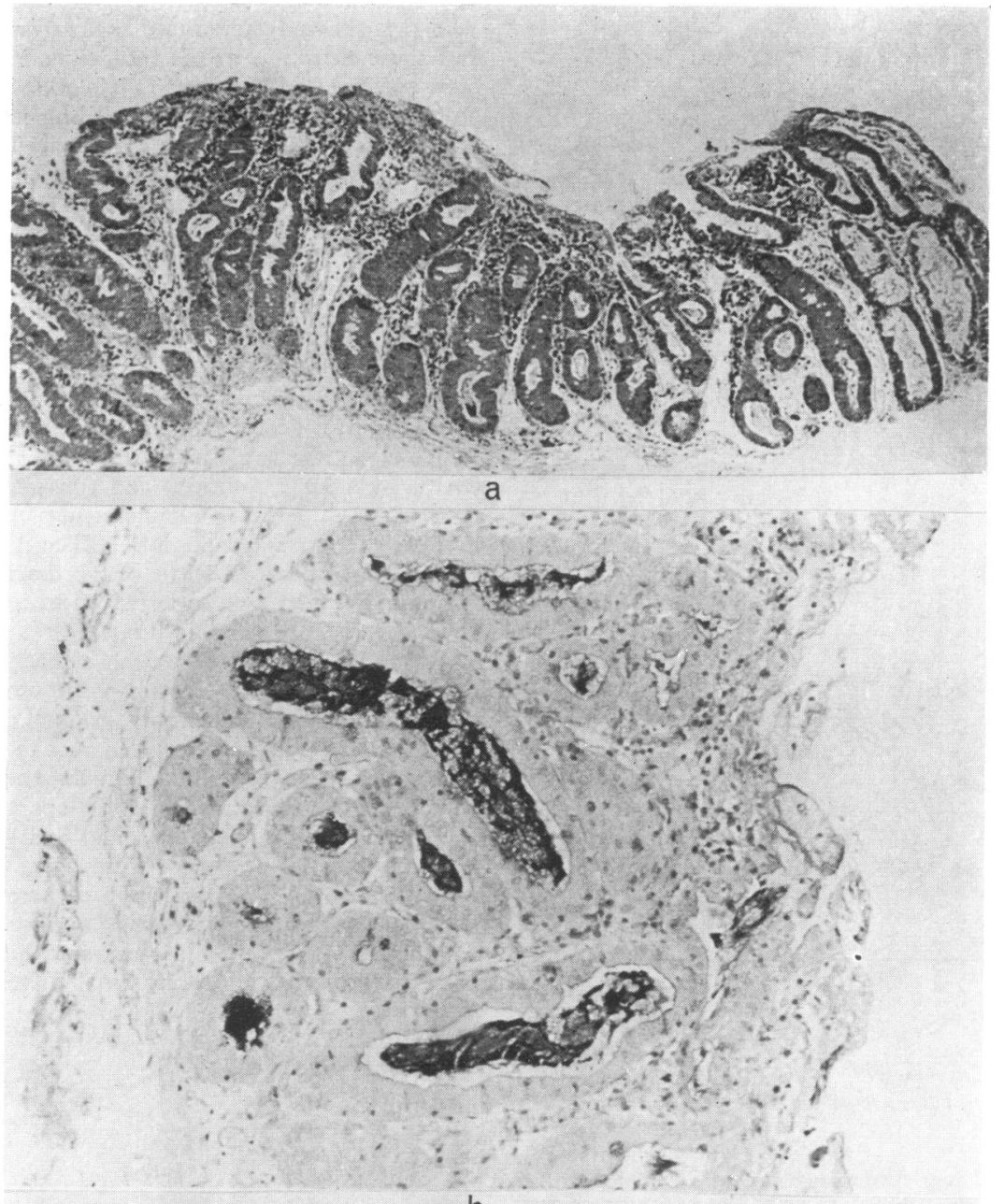

b

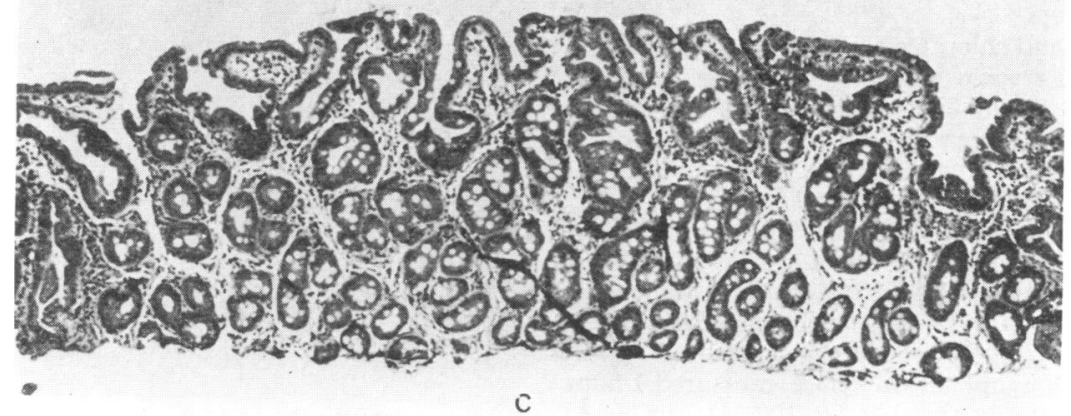

FIG. 6.-Case 2. Jejunal mucosal biopsies (a) before gluten withdrawal ( $H$ and $E . \times 40.),(b)$ before gluten withdrawal $(P A S . \times 131),.(c) 5$ months after gluten withdrawal $(H$ and $E . \times 40$.$) .$ 
There was no clinical evidence of hypocalcaemia. Investigations showed serum calcium $8.4 \mathrm{mg} / 100 \mathrm{ml}$, serum total protein $5.8 \mathrm{~g} / 100 \mathrm{ml}$, and a low 24-hour urinary calcium excretion of $44 \mathrm{mg}$ during a period of normal calcium intake. A bromsulphalein excretion test and measurement of prothrombin time were normal. Oesophagoscopy did not confirm the presence of the varices suggested on the barium swallow. $5 \mu \mathrm{Ci}^{51} \mathrm{CrCl}_{3}$, given intravenously in order to detect a protein-losing enteropathy, resulted in the appearance in the stools over a 5-day period of more than $13 \%$ of the injected dose. An excretion of $1 \%$ or less over 5 days has been recorded in 9 control adult subjects, and a range of $1 \cdot 1$ to $7.4 \%$ in 9 adult patients with coeliac disease (Walker-Smith, Skyring, and Mistilis, 1967).

A peroral jejunal mucosal biopsy specimen had a flat honeycomb appearance on dissecting microscopy. Histological examination showed an absence of villi, flattened surface mucosal cells, no Giardia lamblia, a cellular infiltration of the lamina propria (Fig. 6a), and crypts distended with secretions (Fig. 6b). These findings were compatible with the usual findings in coeliac disease, and at the same time supported the diagnosis of cystic fibrosis.

The introduction of a gluten-free diet resulted in a $0.5 \mathrm{~kg}$ gain in weight during the first week, and an improvement in temperament. This improvement continued at home.

On re-admission 5 months after gluten withdrawal, she looked very fit and happy (Fig. 5b) and had gained $6.6 \mathrm{~kg}$ in weight (Fig. 4). Abdominal distension had decreased. Haematological and biochemical investigations were normal, including the 1-hour blood xylose level, which was $34 \mathrm{mg} / 100 \mathrm{ml}$. Another peroral jejunal biopsy was performed, and this showed some improvement compared with the previous biopsy: villi were present, the mucosal cells were columnar and regular, and cellular infiltration of the lamina propria had decreased (Fig. 6c).

\section{Discussion}

These two children, who satisfied diagnostic criteria for both cystic fibrosis and coeliac disease, showed interesting clinical features during the acute phases of their illnesses. The mucosal appearance of the first biopsy specimen on Case 1 was not completely flat, and it may be reasonable to ascribe this to the very low gluten intake which preceded biopsy. This same patient deteriorated after admission to hospital, and continued to do so, even after jejunal biopsy and the withdrawal of both gluten and lactose from her diet. She presented the picture of 'coeliac crisis'-gross abdominal distension, very large fluid stools, and disturbed homoeostasis. Corticosteroids have improved the symptoms of adult patients with coeliac disease (Wall et al., 1970) and intravenous resuscitation and the administration of corticosteroids have been recommended to treat the coeliac crisis state in children (Lloyd-Still et al., 1972); this treatment was effective in our patient.

With regard to Case 2, it was possible during the first admission to offer a number of explanations for the prolonged diarrhoea and vomiting, alkalosis, hypocalcaemia, manifestations of malabsorption, and abnormal liver function tests. Several factors may have been operating, either alone or in combination: functional intestinal obstruction or 'meconium ileus equivalent', seen in older patients with cystic fibrosis; an anicteric episode of infective hepatitis, several cases of infective hepatitis having occurred in the neighbourhood in which this child had been living; chronic malnutrition, which has been recorded as a cause for raised transaminase levels (Baron, 1960); and chronic biliary cirrhosis, often present in CF, may have contributed to the abnormal liver function tests, including the low serum protein values and prolonged prothrombin time. However, a significant degree of biliary cirrhosis was considered improbable as the spleen was not palpable at any time, and oesophageal varices, though suggested by barium swallow, were not confirmed on oesophagoscopy. Hypoparathyroidism was an unlikely explanation for the low serum calcium values as the serum phosphate levels were never raised. The child's initial clinical improvement and later relapse with a further fall in serum proteins, calcium, and magnesium indicated that a further explanation should be sought. It is highly probable that the low values for $\mathrm{Hb}$, folic acid, serum protein, calcium, and magnesium, the abnormal coagulation studies, and possibly the raised transaminase levels could be explained on the basis of mucosal malabsorption due to coeliac disease, the pancreatic enzyme deficiency of CF being a contributory factor and causing impairment of intraluminal digestion.

Abnormalities of calcium metabolism in CF are being debated. Some exocrine fluids are reported to contain high calcium concentrations (Warton and Blomfield, 1971), but serum calcium levels in the absence of hypoproteinaemia are usually considered to be within normal limits (Lowe, May, and Reed, 1949; di Sant'Agnese and Talamo, 1967). We feel, in retrospect, that all symptoms during the 7-month period of her more acute illness, with the possible exception of the enlarged tender liver, are explained by the two diagnoses of cystic fibrosis and coeliac disease. No weight gain was achieved during a 3-year period preceding the first hospital admission, and this may have been due to the effects of coeliac disease. An episode of infective hepatitis cannot be disproved; it is unlikely, however, that such an infection, anicteric and presumably mild, would 
have contributed substantially to the clinical situation.

Figures given for the incidence of $\mathrm{CF}$ among Caucasian populations of European origin are usually of the order of $1: 2000$ to $1: 2500$. Danks, Allan, and Anderson (1965) in Australia, and Hall and Simpkiss (1968) in England, quote similar figures of 1:2448 and 1:2358, respectively. Incidence reports for coeliac disease have been more variable. Black (1964), whose diagnostic criteria did not include jejunal biopsy, estimated an occurrence in Glasgow of 1:1778. McCrae (1970), whose cases were diagnosed with the aid of jejunal biopsy but whose survey did not include biopsy evidence from asymptomatic relatives, gave an incidence in Glasgow of $1: 1850$. Family studies by MacDonald, Dobbins, and Rubin (1965) and by R. T. Shipman and co-workers (personal communication, 1973) have shown that a number of asymptomatic relatives have small bowel lesions characteristic of coeliac disease. From these findings it could be inferred that the true incidence of coeliac disease is somewhat higher. Mylotte et al. (1973) reported an incidence in children in the west of Ireland (Eire), among a Celtic population, of approximately 1:500, a figure which may not be applicable to all areas in England and Wales.

If the incidences of $\mathrm{CF}$ and coeliac disease are taken as 1:2500 and 1:2000 at birth, and if a 15\% mortality occurs in CF between the time of birth and the beginning of the 4th year (by calculation from a report by George and Norman (1971) Tables I and IV), then the expected incidence of both disorders occurring in the same individual is $1: 5.9$ million. There are some 4.7 million children only in England and Wales who are of ages 1 to 6 years; thus, in this age group, by chance alone, even one child with coexistent CF and coeliac disease is not expected; in fact ' 0.80 ' of a child is expected. Some $10 \%$ of the child population may, if sick, attend hospitals in the Birmingham region, and a proportion of these children, which is certainly less than $50 \%$, may be referred to our unit. Thus, if the actual incidence of coeliac disease is $1: 2000$, then ' 0.04 ' of a child may be expected to attend our clinic; and if the incidence is really as high as 1:500, as suggested by Mylotte et al. (1973), then ' 0.16 ' of a child may be expected at our clinic. Two such children attend. It may be argued that it is unlikely that these two disorders have occurred together by chance alone.

If coincidence is an incorrect explanation for the combined incidence of these two diseases, then the remaining possibilities are that one condition predisposes to the development of the other, or that these children suffer from a previously undescribed illness which has the features of both CF and coeliac disease. A report by Stokes et al. (1972) on the distribution of histocompatibility antigens associated with adult coeliac disease may give a clue as to which of these possibilities is more likely to be correct. In their study the frequency of HL-A antigens 1 and 8 occurring together in 49 adult patients with coeliac disease was $75.5 \%$, the combined frequency of these antigens in a control population of 268 people being $20 \cdot 1 \%$. The frequency of HL-A antigens 1 and 8 occurring in children with coeliac disease is similar to that of adult coeliac disease patients (McNeish, Nelson, and Mackintosh, 1973). The distribution of white cell antigens in a group of 35 CF children is similar to that of a control group (M. C. Goodchild, K. P. Glenn, P. Mackintosh, and J. H. Edwards, in preparation). Our two patients, Cases 1 and 2, both have an HL-A phenotype which includes the antigens 1 and 8 . If there were a 'new' disorder presenting with the features of $\mathrm{CF}$ and coeliac disease, it is unlikely that both these children would have the HL-A phenotype known to be commoner in coeliac disease. Using the figures reported by Stokes et al. (1972), the likelihood of our two patients having true coeliac disease is $0.75 \times 0.75$, or 0.56 , compared to the likelihood that they have a new syndrome, where the phenotype presumably would be normal, of $0.20 \times 0 \cdot 20$, or 0.04 . These have a ratio of $14: 1$ in support of coeliac disease, and against the existence of a new syndrome.

Thus, we conclude that an incidence of CF and coeliac disease together, which is greater than that expected by chance, may be explained by one of the two diseases present predisposing to the development of the other. Since CF is certainly present from birth, and the features of coeliac disease develop later, it seems more probable that the presence of $C F$, possibly in a child with a high risk HL-A phenotype, predisposes to the development of coeliac disease.

If these conclusions are correct, an effort should be made to identify those children who have the dual problem. Jejunal biopsy may be considered with reluctance when a diagnosis of CF has been made. However, there may be a place for this investigation in certain patients; in particular, in those who have the HL-A phenotype which includes the antigens 1 and 8 , and who have marked retardation of growth, temperamental difficulties, and a failure to thrive, which on clinical and on biochemical evidence is judged to be disproportionate to the pulmonary state. 
We thank Professor J. H. Edwards for advice on aspects of genetics; Drs. A. H. Cameron and I. ForrestHay for biopsy photographs; and the Departments of Medical Illustration at the Children's Hospital and at the Queen Elizabeth Hospital, Birmingham. M.C.G. is in receipt of a grant from the Cystic Fibrosis Research Trust.

\section{REFERENCES}

Baron, D. N. (1960). Serum transaminases and isocitric dehydrogenase in kwashiorkor. Fournal of Clinical Pathology, 13, 252.

Black, J. A. (1964). Possible factors in the incidence of coeliac disease. Acta Paediatrica, 53, 109.

Challacombe, D. N., Brown, G. A., Black, S. C., and Storrie, M. H. (1972). Increased excretion of 5-hydroxyindoleacetic acid in urine of children with untreated coeliac disease. Archives of Disease in Childhood, 47, 442.

Danks, D. M., Allan, J., and Anderson, C. M. (1965). A genetic study of cystic fibrosis of the pancreas. Annals of Human Genetics, 28, 323.

George, L., and Norman, A. P. (1971). Life tables for cystic fibrosis. Archives of Disease in Childhood, 46, 139.

Gracey, M., Burke, V., and Anderson, C. M. (1969). Treatment of abdominal pain in cystic fibrosis by oral administration of n-acetyl cysteine. Archives of Disease in Childhood, 44, 404.

Hall, B. D., and Simpkiss, M. J. (1968). Incidence of fibrocystic disease in Wessex. Fournal of Medical Genetics, 5, 262.

Hide, D. W., and Burman, D. (1969). An infant with both cystic fibrosis and coeliac disease. Archives of Disease in Childhood, 44, 533.

Lloyd-Still, J. D., Grand, R. J., Khaw, K-T., and Shwachman, H. (1972). The use of corticosteroids in celiac crisis. Fournal of Pediatrics, 81, 1074.
Lowe, C. U., May, C. D., and Reed, S. C. (1949). Fibrosis of the pancreas in infants and children. A statistical study of clinical and hereditary features. American Fournal of Diseases of Children, 78, 349.

McCrae, W. M. (1970). The inheritance of coeliac disease. In Coeliac Disease, p. 55. Ed. by C. C. Booth and R. H. Dowling. Churchill Livingstone, Edinburgh and London.

MacDonald, W. C., Dobbins, W. O., and Rubin, C. E. (1965). Studies of the familial nature of celiac sprue using biopsy of the small intestine. New England fournal of Medicine, 272, 448.

McNeish, A. S., Nelson, R., and Mackintosh, P. (1973). (Letter.) H-LA 1 and 8 in childhood coeliac disease. Lancet, 1, 668.

Mylotte, M., Egan-Mitchell, B., McCarthy, C. F., and McNicholl, B. (1973). Incidence of coeliac disease in the west of Ireland. British Medical fournal, 1, 703.

di Sant'Agnese, P. A., and Talamo, R. C. (1967). Pathogenesis and physiopathology of cystic fibrosis of the pancreas. New England Fournal of Medicine, 277, 1344.

Stokes, P. L., Asquith, P., Holmes, G. K. T., Mackintosh, P., and Cooke, W. T. (1972). Histocompatibility antigens associated with adult coeliac disease. Lancet, 2, 162.

Tomarelli, R. M., Charney, J., and Harding, M. L. (1949). The use of azoalbumin as a substrate in the colorimetric determination of peptic and tryptic activity. Fournal of Laboratory and Clinical Medicine, 34, 428.

Walker-Smith, J. A., Skyring, A. P., and Mistilis, S. P. (1967). Use of ${ }^{51} \mathrm{CrCl}_{3}$ in the diagnosis of protein-losing enteropathy. Gut, $8,166$.

Wall, A. J., Douglas, A. P., Booth, C. C., and Pearse, A. G. E. (1970) Response of the jejunal mucosa in adult coeliac disease to oral prednisolone. Gut, 11, 7 .

Warton, K. L., and Blomfield, J. (1971). Hydroxyapatite in the pathogenesis of cystic fibrosis. British Medical fournal, 3, 570.

Correspondence to Dr. Mary C. Goodchild, Institute of Child Health, Francis Road, Birmingham B16 8ET. 